\title{
EL CENTRO HISTÓRICO DE PISAQ, VALORACIÓN PATRIMONIAL Y MIRADA ACTUAL
}

\section{THE HISTORICAL CENTER OF PISAQ, HERITAGE VALUATION AND CURRENT REVIEW}

\author{
Anli Chalco Salas \\ Universidad Nacional Mayor de San Marcos, Perú \\ Ángel Delgado Flores \\ Consultor Independiente, Perú \\ José Hayakawa Casas \\ Universidad Nacional de Ingeniería, Perú
}

\section{RESUMEN}

El presente artículo forma parte de una investigación referida a la gestión del patrimonio edificado con una atención especial en la casuística peruana, enriquecida por el cruce de miradas disciplinares en torno a la arqueología, la arquitectura, la conservación del patrimonio edificado y la gestión urbano-cultural, frente al desarrollo urbanístico y el impacto negativo sobre el paisaje urbano. Por tanto, resulta ser una investigación en proceso que pretende ser una reflexión de largo alcance sobre las potencialidades del binomio territorio-patrimonio, logrado mediante el registro fotográfico, revisión y recopilación de fuentes documentales y planimétricas. El caso elegido se desarrolló en el distrito de Pisaq, actualmente poseedor de un centro histórico muy tradicional, que conserva un trazado urbano en forma de damero y una arquitectura perteneciente al periodo virreinal y republicano, todos emplazados sobre un sistema de andenería inca. Expresando de esta forma características muy singulares que reflejan una perfecta integración entre el hombre y la naturaleza.

Palabras clave: periodo virreinal, periodo republicano, patrimonio edificado y gestión urbano-cultural.

Este es un artículo Open Access bajo la licencia Creative Commons AtribuciónNoComercial-Compartirlgual 4.0 


\begin{abstract}
This article is part of an investigation related to the management of the built heritage, with special attention in the Peruvian cases, enriched by the crossing of disciplinary perspectives on archeology, architecture, conservation of built heritage and urban management -cultural versus urban development and the negative impact on the urban landscape. It is therefore a research in process, which aims to be a far-reaching reflection on the potentialities of the territory-heritage binomial, achieved through photographic registration, review and compilation of documentary and planimetric sources. The case was developed in the district of Pisaq, which currently has a very traditional historic center that preserves an urban layout in the form of checkerboard and an architecture belonging to the Viceroyal and Republican period, all located on a system of Inca terraplens. Expressing in this way very unique characteristics that reflect a perfect integration between man and nature.
\end{abstract}

Keywords: Viceroyal period, Republican period, built heritage and urban-cultural management.

\title{
Cuestión previa
}

La presente investigación se desarrolla con el objetivo principal de presentar una mirada de conjunto y actual sobre el patrimonio monumental del poblado de Pisaq, ubicado en el distrito de Pisaq, provincia de Calca y región Cusco, a partir de lo cual, se formulan lineamientos para su gestión eficaz. Para ello, la metodología del estudio consideró diversas sesiones de trabajo de campo recabando información testimonial y fotográfica in situ, revisión de documentos normativos y de planeamiento sectorial (cultural y urbana) relacionada al tema, consulta a expertos y actores sociales de la localidad y referencias de investigaciones que permitan elaborar un encuadre teórico e histórico del objeto de estudio.

\section{El Centro Histórico de Pisaq (CHP)}

\section{Ubicación}

El distrito de Pisaq está ubicado a $2981 \mathrm{~m}$ s. n. m., pertenece a la provincia de Calca, departamento del Cusco, al inicio del Valle Sagrado de los Incas (Figura 1). Actualmente el CHP ocupa un área de $73586 \mathrm{~m}^{2} \mathrm{con}$ un perímetro de 1107 m lineales, ubicado dentro de las coordenadas geográficas E/ 191305 y N/ 8514524 . Sus limites son:

- $\quad$ Por el norte : Comunidad campesina de Viacha

- Por el sur : Comunidad campesina de Huandar

- Por el este : Distrito de Qolqepata

- Por el oeste : Distrito de Taray 
Figura 1. Plano de ubicación del distrito de Pisaq.

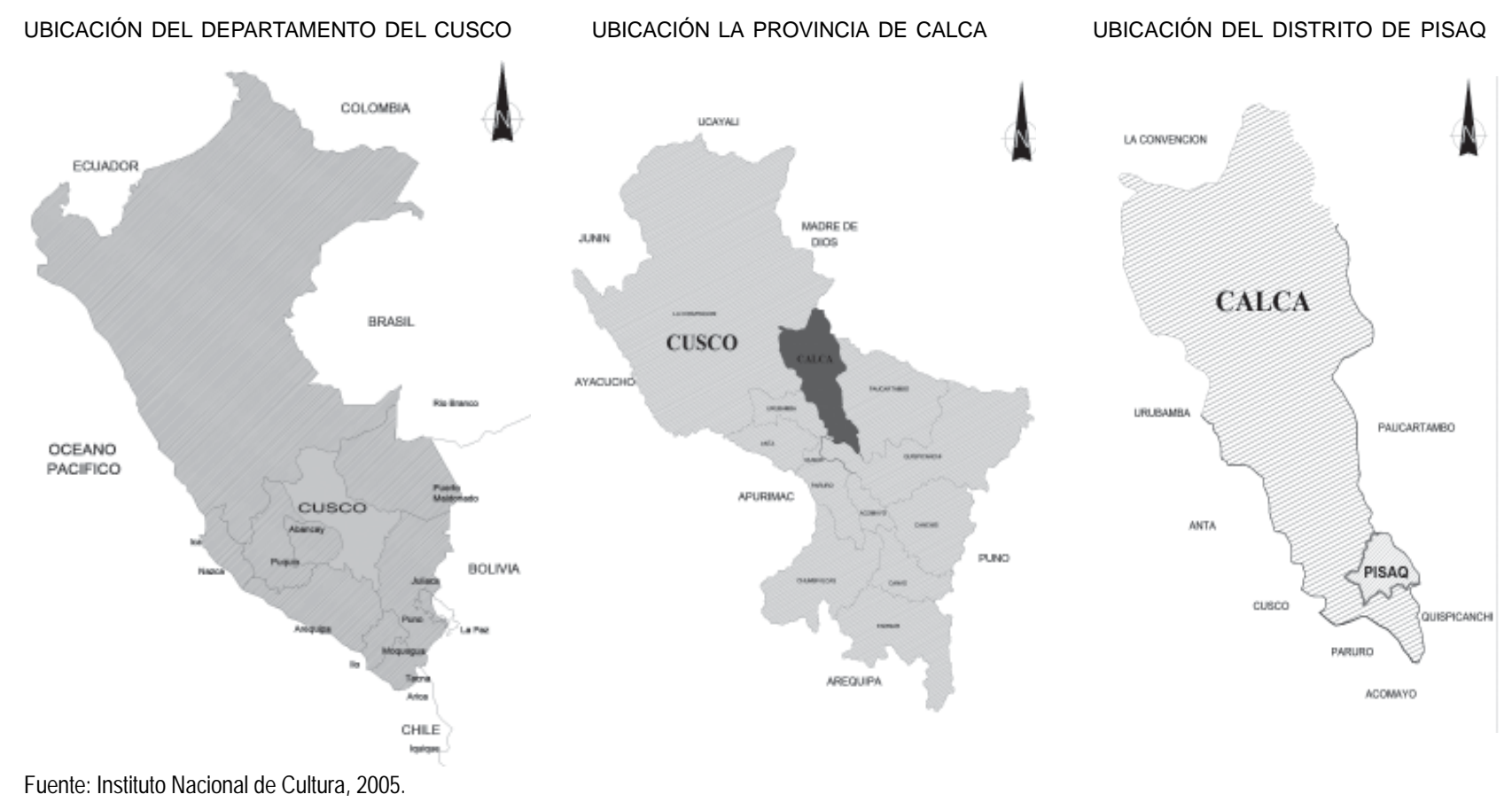

\section{Evolución urbana a través de su historia}

Según la cronología asignada por Bauer (2008) para el Valle del Cusco, Pisaq, fue un espacio ocupado y controlado posiblemente desde el periodo Arcaico Tardío (5000-2200 a. C.):

Al igual que sus predecesores, los pueblos del Arcaico Tardío en la sierra central son identificables arqueológicamente como pequeños grupos que cazaban y cosechaban plantas silvestres. Sin embargo, para finales de esta fase, muchos de estos grupos habían crecido bastante y se habían convertido en semi-sedentarios, dedicándose a algunas formas de horticultura temprana e incipiente domesticación animal. (p. 73)

Ubicando inicialmente sus asentamientos en la cima de las montañas a más de $4000 \mathrm{~m} \mathrm{~s}$. n. m. Posteriormente Bauer (2008) señala que en el periodo Formativo (2200 a. C. - 200 d. C.) se desarrollaron las sociedades jerarquizadas, como los Cuyos y los Ayarmacas quienes descendieron y ocuparon toda la cuenca del río Chuncuy, hasta la llegada de los incas.

Los Ayarmacas desempeñaron un rol importante en los inicios del Cusco, ellos sostuvieron prolongadas luchas contra los incas, y solo cuando surgió el Tahuantinsuyu quedaron definitivamente desbaratados y relegados al cargo de simples curacas locales, jefes de unos cuantos ayllus. (como se citó en Rostworowski, 1999, p. 31) 
Según la recopilación histórica del ex Instituto Nacional de Cultura - INC (2010) para la obra Restauración, restitución volumétrica y puesta en valor del MHA: Templo San Pedro Apóstol de Pisac, al Inca Pachacutec se le atribuye la construcción de la ciudad de Cusco y la expansión del territorio del Tawantinsuyo. Por las características constructivas presentes en el monumento arqueológico de Pisaq, Kaulicke, Kondo, Kusada y Zapata (2003) señalan:

No se duda que todo el complejo pertenezca a tiempos incaicos. Sobre la base de las evasivas menciones en las fuentes tempranas, se acepta, por lo general, que se trata de una sola obra de Pachacutec Inca, atribución fortalecida por estudios arquitectónicos comparativos con otros sitios asignados al mismo inca. (p. 73)

Desde entonces se ampliaron los terrenos de cultivo con la construcción de andenerías y toda la infraestructura necesaria para su buen funcionamiento hacia el piso del valle. Según el ex INC (2010) debió ser una capital regional muy importante por su ubicación, bondad de tierras, extensión de sus laderas y fajas ribereñas. Ya en el periodo virreinal, según la información recopilada por el ex INC (2005) para la elaboración del Plan Maestro del Parque Arqueológico de Pisaq (PMPAP), Pisaq es fundada en el año 1572 d. C., por el Virrey Francisco de Toledo, con una trama urbana inicial de tipo damero o cuadrícula emplazada en el piso de valle para el mejor control de los tributos. Con una plaza central donde se debían ubicar las principales instituciones como el cabildo y la Iglesia; es en este periodo, donde se van formando también las aún actuales haciendas de San Luis, Sañu Huasi, Juq’ui y Ayñas, esta última hoy conocida como el Hotel Royal Inka.

En el periodo republicano, el distrito va cambiando sus características urbanísticas virreinales, siendo Pisaq, reconocido como distrito en 1825 por el General Bolívar donde las viviendas se caracterizaban por tener la configuración de las casas quinta y arquitectura dispersa hasta la década de 1960, época en la que se promulga la Ley de Reforma Agraria por medio del cual los terrenos de cultivo más extensos son distribuidos (INC, 2010).

Y es a partir de 1980 que va presentando cambios en su estructura urbana, debido a los trabajos y estudios que realiza el Plan Copesco, como es el acondicionamiento urbano del poblado y los trabajos de intervención y recuperación de algunos conjuntos arqueológicos, aumentando la densidad constructiva y poblacional de esta parte del poblado (INC, 2005), tiempo desde el cual la población va creciendo hacia las periferias del centro histórico de Pisaq. Desde entonces hasta hoy, el aspecto ya alterado, está acompañado de la proliferación de nuevas construcciones que crecen en forma vertical. Pese a esto, cabe resaltar que la mayoría de las viviendas aún conservan el uso residencial como lo describe Navarro: "El mayor uso sigue siendo residencial, alternando con la vivienda huerto, la vivienda comercio o la vivienda taller” (2014, p. 158).

\section{Estado actual del espacio urbano y su patrimonio cultural edificado}

\section{Morfología y conformación urbana}

La singular composición de la traza urbana del CHP a la que nos hemos referido anteriormente, es de por sí misma un elemento de valoración cultural de similar importancia como los inmuebles patrimoniales que hasta 
hoy perviven en él, tal y como sucede en otros centros históricos de fundación española en Latinoamérica. Por lo tanto, su valoración como bien cultural, no solamente recae en la presencia de los elementos inmuebles prehispánicos, virreinales y republicanos que contiene, sino también en la conformación espacial, morfología del poblado y su relación con el ambiente natural y las estructuras prehispánicas, como andenerías y conjuntos urbanos aledaños.

Es así que para comprender el devenir de las transformaciones del poblado y su actual conformación urbana, debemos referirnos primeramente a su crecimiento demográfico, el cual comienza a ser visiblemente acelerado a partir de la década de 1980, con posterioridad a la creación del Parque Arqueológico de Pisaq (PAP), lo cual da un impulso positivo a la incipiente actividad turística que transforma el poblado de agricultores en un mercado productor internacional de artesanías, pasando de una económica basada en la agricultura a una economía basada en el turismo, fenómeno que es fortalecido a partir de la década de 1990 como consecuencia de la derrota del terrorismo, lo cual facultó la reactivación de la economía y el desarrollo progresivo de la actividad turística en el interior del país.

Estas circunstancias promovieron el asentamiento de una nueva población y, por ende, también el desarrollo del centro poblado con la instalación de nuevas áreas de servicios de salud, educación, etc., lo que conlleva a la generación de nuevas áreas urbanas, las mismas que se establecen de manera arbitraria y sin seguir ningún patrón ordenado o planificado, teniendo impactos negativos en la estructura urbana del poblado y el paisaje urbano. Según Torrely y Campana, "los cambios más trascendentales en la estructura urbana, se han dado en las últimas dos décadas primero con el fenómeno migratorio (...) y el cambio en las actividades económicas” (1994, p. 22). Atendiendo a la actual estructura urbana del poblado, a su consolidación desigual y al documento del Plan de Desarrollo Urbano (PDU) de Pisac del año 2011, elaborado por el Centro Guaman Poma de Ayala, es posible determinar sectores o zonas de características de ocupación homogéneas (Figura 2):

Figura 2. Esquema de ocupación del poblado de Pisaq.

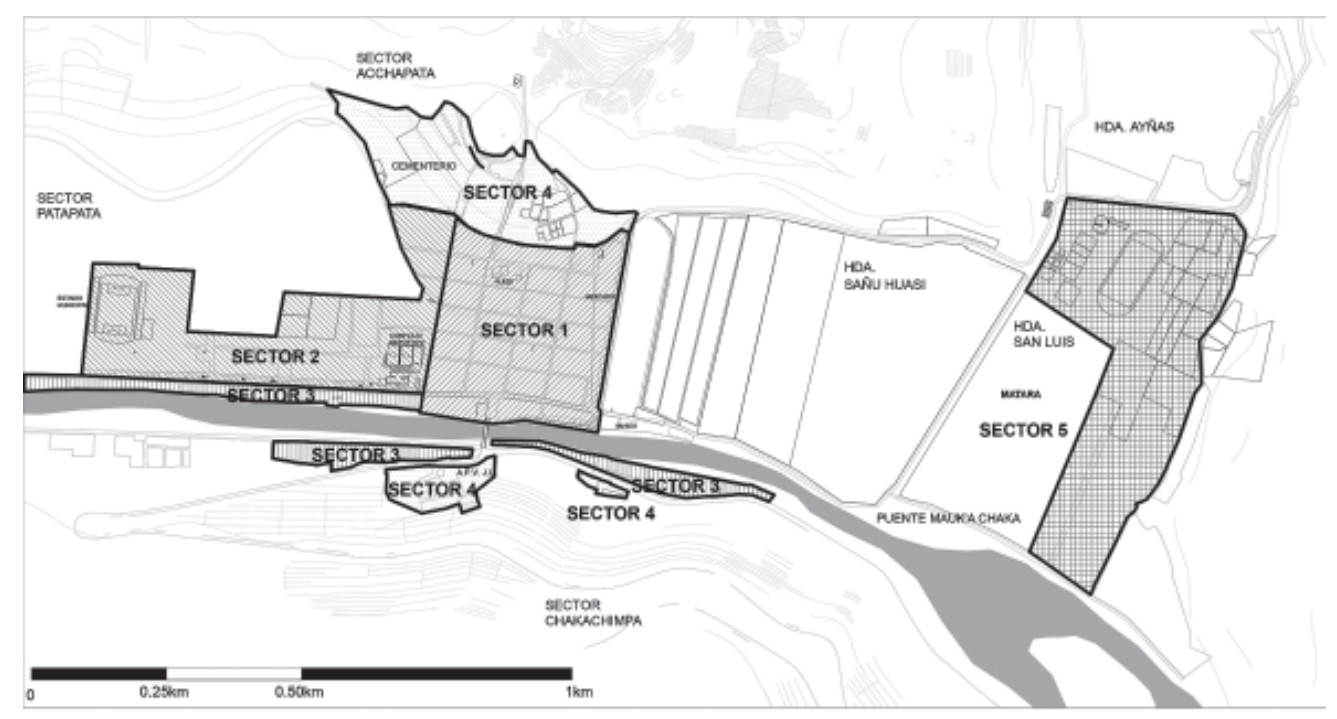

Fuente: Elaborado en base a la información de la Tesis de Torrely y Campana, 1994. 
- Sector 1: Correspondiente al poblado virreinal claramente diferenciable por la disposición ortogonal de sus manzanas y calles estrechas, donde todo el conjunto está dispuesto y organizado alrededor de la plaza principal. El CHP, así determinado por la Dirección Desconcentrada de Cultura de Cusco se halla inmerso en este sector.

- Sector 2: Es el sector que concentra los principales equipamientos urbanos del poblado (Institución Educativa Bernardo Tambohuacso Pumayali - IEBTP, estadio municipal, centro de salud y complejo deportivo), la distribución de manzanas es distinta a la del Sector 1, aquí las manzanas son de forma alargada y se distribuyen a lo largo de la avenida Ausangate.

- Sector 3: Correspondiente a las ocupaciones en las fajas marginales del río Vilcanota, el asentamiento es de carácter arbitrario y las edificaciones se han constituido una tras otra sin previsión de orden, articulación vial planificada, ni atención al nivel de peligro por inundación, no existen áreas de aporte y la instalación de servicios es precaria.

- Sector 4: Básicamente en este sector se agrupan las ocupaciones en zonas de laderas, sin planificación alguna, con manzanas irregulares, además de ocupar y depredar áreas con compromiso arqueológico importante como los sistemas de andenerías del sector de Chakachimpa. En este lugar se consideran las ocupaciones hacia las zonas Norte (andenes de Acchapata) y Sur (andenes de Chakachimpa).

- $\quad$ Sector 5: Estas ocupaciones se dan hacia el lado Este del poblado, con edificaciones dispersas en grandes lotes que albergan principalmente población flotante.

Podemos inferir entonces, que el crecimiento urbano se establece primeramente alrededor de la zona monumental para posteriormente, debido a la demanda habitacional, ocupar zonas libres cercanas a los equipamientos establecidos; ejemplo de ello es la construcción de la institución educativa, mencionada líneas arriba, que se edifica aislada del centro urbano y a un lado de la carretera Pisaq-Calca y, la posterior constitución de asociaciones pro vivienda en las márgenes del río Vilcanota y entre el espacio generado entre la institución educativa y los límites del centro poblado ocupando una tradicional zona agrícola del grupo de andenerías Patapata.

Si bien, por lo expuesto puede atribuirse al desarrollo de la actividad turística el factor crecimiento del poblado, son percibibles también otros factores, ligados al atractivo de Pisaq por su situación geográfica, su relación física con el valle sagrado y la cercanía a la ciudad del Cusco, que en los últimos años han provocado la transformación informal del uso de suelo agrícola de alta productividad por suelo residencial y comercial como el caso de las áreas ubicadas al Este del poblado, que alberga edificaciones para población flotante de fines de semana (como se aprecia en la Figura 2, sector 5).

“En los últimos 30 años en el poblado se presenta un proceso de crecimiento y expansión urbana acelerada, generando la ocupación de áreas agrícolas con compromiso arqueológico, densificando áreas y manzanas urbanas, alterando la trama urbana original del poblado histórico” (INC, 2005, p. 121). Este crecimiento no planificado evidencia el desarrollo de un negocio de mayor rentabilidad económica en el corto plazo, y ha impactado negativamente en la imagen urbana del CHP y por ende en la valoración estética que le concedía su legado 
patrimonial, tal y como lo manifiesta el INC (Figura 3). Una de las consecuencias de esto último que señalamos, se hace evidente al vislumbrar el centro poblado desde lo alto de la carretera de acceso Cusco-Pisaq, siendo una de las cosas más llamativas negativamente, la presencia de cubiertas plásticas y carpas en la plaza principal y alrededores. Para cualquiera que conozca el poblado de Pisaq esta situación no es nueva, la flagrante falta de autoridad e irrespeto por el espacio público se consuman en la ocupación informal e ilegal de comerciantes de artesanías y souvenirs justamente en la zona que debiera ser de mayor protección, es decir su centro histórico.

Figura 3. Vista aérea del poblado de Pisaq.

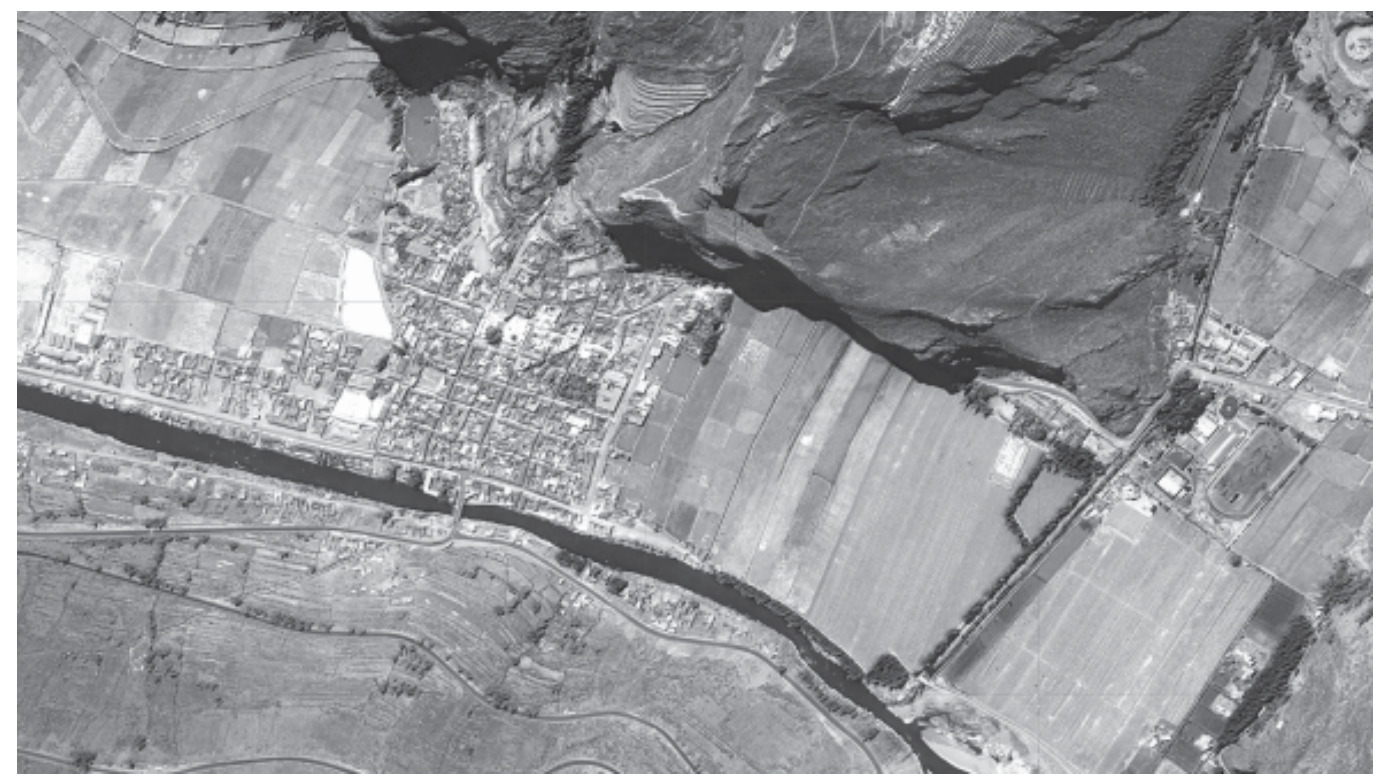

Fuente: Ministerio de Comercio Exterior y Turismo, 2007.

Tal situación es conocida por la autoridad rectora del patrimonio cultural en el país, pero hasta la fecha se ha hecho muy poco por revertirla. "Existe una Invasión y/o ocupación ilegal de ambientes, espacios o áreas originalmente abiertas o libres, asociados a las estructuras urbano-arquitectónicas, tales como plazas, calles, patios; con fines de ampliación de espacios y ambientes para diversos usos” (INC, 2005, p. 172).

Podemos afirmar que el referido problema es de larga data, y surgió a partir de una modificación de la actividad comercial del trueque de productos que se llevaba a cabo en la plaza principal, haciendo uso temporal del espacio público hasta no hace muchos años, para luego decaer en una feria permanente de productos artesanales y souvenirs a raíz también de la importancia que tomó el Parque Arqueológico de Pisaq, como atractivo turístico de primer orden durante la década de 1980. Esta ocupación indebida del espacio público contraviene no solamente aquello que establece la ley, sino también atenta contra el derecho ciudadano al libre tránsito y al uso y disfrute de las vías; además de permitir el usufructo económico del espacio público a favor de solamente unos cuantos. 
Las consecuencias negativas son pues muchas y abarcan temas de seguridad, salubridad, ornato, etc., afectando obviamente de manera directa la conservación del patrimonio edificado del CHP y; también de manera menos explícita a las manifestaciones del patrimonio inmaterial, ya que estas deberían encontrar en el espacio público su principal lugar de desenvolvimiento, esencialmente por las características que tienen estos de ser parte del colectivo (Figura 4).

Figura 4. Niños en la Plaza Constitución, celebrando el Día Internacional de los Monumentos y Sitios en un día atípico, donde el espacio público fue liberado de la invasión publica.

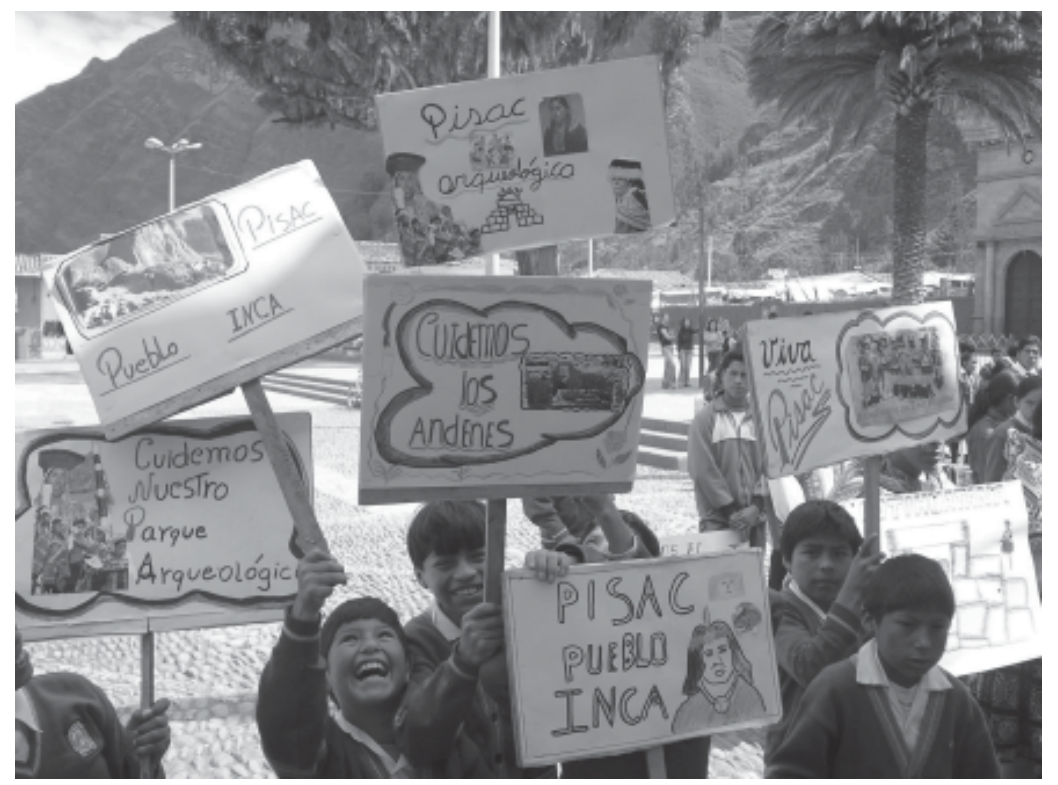

Fuente: Archivo fotográfico personal, 2008.

Asimismo, la ausencia de instrumentos normativos y técnicos que orienten la ocupación eficaz del territorio, ha tenido como consecuencia una deficiente gestión del mismo y de sus sistemas urbanos; tal es el caso de los espacios públicos ya mencionados o la movilidad donde el inadecuado tratamiento del sistema vial y la presión del turismo, han acarreado algunos problemas como los que se detallan a continuación:

- Invasión desmedida y uso descontrolado de las vías locales en el CHP, las mismas que son estrechas y sin veredas pero que, sin embargo, son ocupadas a diario por vehículos mayores como buses de turismo y particulares, lo cual atenta contra la seguridad de los peatones y las edificaciones, por usar las vías como estacionamiento, hecho que se podría controlar mediante una ordenanza que priorice el uso peatonal, ya que hablamos de distancias que pueden ser fácilmente recorridas a pie, sumado a la instalación de un paradero formal para buses de transporte turístico en un lugar apto.

- De acuerdo al documento de trabajo del Plan de Desarrollo Urbano de Pisac, otro de los problemas observables es la deficiente articulación vial de los sectores de ocupación reciente (sectores 4 y 5, descritos anteriormente) con el núcleo del poblado, y es que en estos sectores la ocupación ha sido espontánea y no ha previsto ni siquiera la continuidad de calles. 
- Se observa también un fenómeno de superposición vial muy frecuente a lo largo de los poblados del Valle Sagrado del Cusco, donde una vía nacional (la carretera Cusco-Pisaq-Calca) se transforma funcionalmente también en vía local, al haberse asentado población en los márgenes de esta. Fenómeno que también se está dando paulatinamente en la zona Sur alrededor de la carretera que comunica con el distrito de San Salvador.

Una forma efectiva de administrar y gestionar el territorio, es justamente contar con los instrumentos técnicosnormativos necesarios, para ello existe el sistema nacional de planificación que marca competencias y responsabilidades de acuerdo a todos los niveles. Refiriéndonos específicamente a los instrumentos técniconormativos de ordenamiento territorial enmarcados en la normativa nacional como el Reglamento de Acondicionamiento Territorial y Desarrollo Urbano Sostenible (DS 022-2016-VIVIENDA), donde los gobiernos locales deben contar (de acuerdo a ciertas características como dimensión y población) con diversos planes de ordenamiento según corresponda. Es así que Pisaq debería tener mínimamente a nivel provincial, un plan de desarrollo concertado, un plan de acondicionamiento territorial y un plan de desarrollo urbano; y a nivel distrital, un plan de desarrollo concertado, planes específicos y esquemas de ordenamiento. De todos ellos, actualmente solo hay en vigencia dos, el Plan de Desarrollo Concertado Provincial de Calca y el plan específico: Plan Maestro del Parque Arqueológico de Pisaq.

El Plan de Desarrollo Concertado Provincial de Calca al 2024 (cf. Ministerio de Comercio Exterior y Turismo, 2007, p. 129 y ss.), aunque habla muy poco del ordenamiento territorial, contempla entre las propuestas de proyectos, el implementar el Plan de Desarrollo Urbano de Calca y el concluir e implementar el Plan de Acondicionamiento Territorial. Respecto a desarrollar instrumentos de gestión territorial para Pisaq, no contempla propuesta alguna. El segundo documento en vigencia, el Plan Maestro del Parque Arqueológico de Pisaq aprobado el año 2009 (INC, 2005) que a la fecha se encuentra desactualizado por ser elaborado por el entonces INC Cusco en el año 2005, contempla entre sus objetivos estratégicos 3, 4 y 5, lo siguiente:

- Promover e implementar programas y proyectos de conservación, recuperación y puesta en valor del patrimonio edificado existente en el poblado histórico y en las áreas rurales, así como regular la zonificación patrimonial, los usos del suelo y el desarrollo urbano existente.

- Regular y ordenar en el poblado histórico las actividades del comercio ambulatorio recuperando las áreas públicas.

- Diseñar e implementar programas que contribuyan a la recuperación y tratamiento del paisaje natural, evitando el deterioro de los suelos, la reducción de las áreas agrícolas y el manejo de residuos sólidos.

Sin embargo, los proyectos propuestos para la consecución de los objetivos estratégicos señalados, han sido parcialmente desarrollados y en la mayoría de los casos dejados de lado; por ejemplo, la elaboración de reglamentación edilicia para la protección del poblado histórico. La escasa implementación del Plan Maestro del Parque Arqueológico de Pisaq (INC, 2005) en los programas propuestos de Arquitectura y asentamientos humanos, y Regulación y ordenamiento de las actividades de comercio ambulatorio condujeron a que los objetivos estratégicos planteados sean solamente buenas intenciones. 
Debemos señalar también en razón de lo expuesto, que la protección de las áreas patrimoniales no recae exclusivamente en velar por lo que ocurre al interior de estas, es decir, al contenido que se halla inmerso dentro de los límites declarados del centro histórico, sino que se extiende a las zonas aledañas las mismas que debieran también ser reglamentadas atendiendo no solamente a la presión urbana y necesidad de suelo urbanizable, sino también a las características patrimoniales y culturales del asentamiento primigenio y la necesidad de su conservación.

Un acierto (respecto a estas consideraciones), es el de incluir en las delimitaciones de los centros históricos sus respectivas áreas circundantes de protección o amortiguamiento cuya reglamentación urbana garantice de alguna manera la conservación de las áreas históricas y la morfología urbana de todo el conjunto. Lamentablemente como se expuso, el poblado de Pisaq carece de los instrumentos técnico-normativos urbanos que, por ejemplo, señalen los parámetros edificatorios básicos para todo el poblado. La carencia de instrumentos de gestión debilita pues la acción, control y fiscalización, habiéndose detectado como lo señala el documento del Plan Maestro del Parque Arqueológico de Pisaq (INC, 2005), habilitaciones urbanas informales, construcciones clandestinas y subdivisiones informales de predios que datan de la época virreinal y republicana.

En cuanto a las habilitaciones urbanas informales, muchas de ellas se han asentado de forma precaria sobre áreas arqueológicas (sectores de: Patapata, Chakachimpa, Acchapata, Huandar, Chongo y Matara Pampa), construcciones clandestinas también se han realizado en patios y canchones de los inmuebles antiguos lo cual altera la trama y el tejido original, además de la volumetría y el emplazamiento de cada vivienda.

Sin embargo y respecto a lo anterior, es pública la existencia de un Plan de Desarrollo Urbano elaborado en el marco del Proyecto Reordenamiento y Rehabilitación del Valle del Vilcanota por el Proyecto Especial Regional Plan COPESCO Cusco, que justamente plantea áreas de tratamiento y usos de suelo diferenciado para cada sector urbano, incluyendo la Zona Monumental declarada todavía el año 1972 (Resolución Suprema 2900-72), considerando también un área circundante a esta; propone además una estructura vial y modos de transporte, un sistema de espacios públicos y equipamiento, disposiciones para el ornato y mobiliario urbano, culminando con un programa de inversiones urbanas estructurado en base a ejes estratégicos, donde dos de ellos (Eje 1: Rehabilitación urbanística integral del Centro Histórico y Eje 5: Revitalización sociocultural y económico) presentan programas y proyectos ligados directamente con el patrimonio cultural del poblado.

Lamentablemente el mencionado documento elaborado a finales del 2011, aún no cuenta con la aprobación respectiva por discrepancias con la Dirección Desconcentrada de Cultura respecto a las zonas de expansión urbana. De continuar este panorama, los problemas de fiscalización y control urbano serán constantes, apelando el municipio a emplear normativa no del todo apropiada para el caso:

Al no contar con un plan de desarrollo urbano y su respectiva reglamentación, los técnicos señalan que estas labores [de regulación del crecimiento urbano] se realizan tomando en cuenta las normas de habilitación urbana y licencias de construcción pertenecientes a las disposiciones generales del RNE 2006. (Navarro, 2014, p. 155) 
Para entender a cabalidad la importancia del legado histórico material del poblado de Pisaq, es necesario también atender a sus muestras individuales, vale decir, a el patrimonio cultural edificado del poblado lo cual se describe sucintamente a continuación.

\section{Patrimonio disperso (arqueológico, histórico y contemporáneo)}

\section{La casa virreinal del siglo XV I- XVII - XVIII ${ }^{1}$}

Las viviendas correspondientes a este periodo se caracterizan, según lo describen Torrely y Campana, por ser:

Edificaciones de dos niveles en planta cuadrada, patio central rodeado de galerías donde el elemento principal es el zaguán de ingreso y escaleras de piedra encajonadas, el ingreso central presenta una portada de piedra y zaguán, como parte central de la fachada, en el segundo nivel de la misma existen ventanas con balcón de tendencia vertical alineadas a los vanos del primer nivel. (1994, p. 71)

Ante lo cual el Plan Maestro del Parque Arqueológico de Pisaq elaborado por el ex INC (2005, p. 167), señala que las construcciones de este periodo son "edificaciones que poseen valor patrimonial y constructivo, (...) con mampostería de adobe y cobertura de teja cerámica. (...) La estructura del techo o cobertura es del tipo par y nudillo”. Entre las casonas más representativas y que mejor se conservan están:

- La Casa Loaiza ubicada en la Av. Amazonas s/n, la cual fue constantemente refaccionada por los propietarios para ser alquilada y darle diversos usos, la cual:

[Consta] de dos niveles en planta rectangular ubicada longitudinalmente, con acceso lateral por medio de portada de piedra con reja de fierro forjado, presenta al interior una galería en el primer nivel con arquerías de piedra que dan acceso a las habitaciones principales ubicadas por debajo del nivel de la calle, la fachada a la Av. Amazonas en simple con vanos de tendencia vertical alineados, algunos de ellos con tallados de madera, otros con enrejados de madera y una puerta del primer nivel con arco de medio punto, lo que indica que ha sufrido modificaciones no muy frecuentes, en la parte superior el alero corrido ha sido colocado encima del mojinete que confirma la esquina. La fachada (...) presenta el acceso principal con arco de medio punto en piedra por el lado izquierdo, al centro presenta acceso a una tienda, sobre el cual se ubica un balcón de madera simple con tejaroz. En la parte posterior presenta un fachada con arquerías de piedra sobre las cuales se ubica una mampara de madera de gran calidad, flanqueada por balcones tallados, (...) su estado de conservación es regular encontrándose en procesos de deterioro sobre todo al interior, señalando además que lo que más atenta actualmente a su imagen es el avisaje publicitario. (Torrely \& Campana 1994, p. 65-67)

1 Acápite parcialmente tomado del Plan Maestro del Distrito de Pisaq 2005. 
- La casa denominada Sara Wasi que está ubicada entre las calles Espinar con Vigil s/n (Figura 5), la cual posee una portada de piedra de jambas con líneas simples, cuyas pilastras de sección rectangular tienen molduras decorativas al igual que el dintel semicircular de siete piezas que soportan para rematar en un cornisamiento poco sobresaliente. De igual forma el interior de la vivienda mantiene las características arquitectónicas de la época virreinal.

Figura 5. Vista panorámica de la Casona, hallada en regular estado de conservación, actualmente funcionan un hospedaje y una imprenta, sin que esto haya significado la modificación de los ambientes.

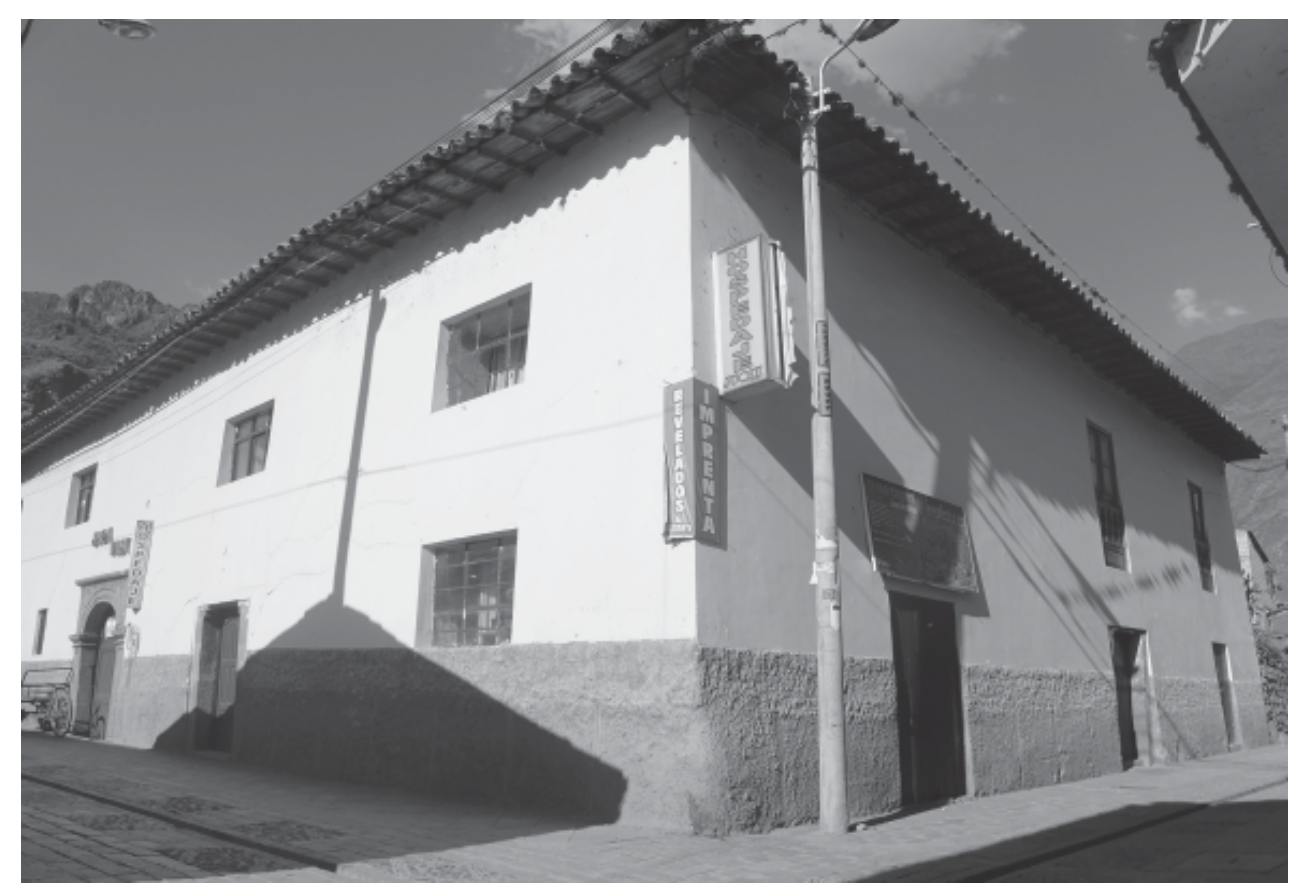

Fuente: Archivo fotográfico personal, 2016.

- La casa de Doña Jesús Antonieta Negrón Alonso, ubicada en la esquina de la Plaza Constitución con la esquina de la calle Bolognesi № 590 y 588 (Figura 6), interiormente fue refaccionada con materiales originales y se halla en buen estado de conservación. Su planta es de forma triangular en razón de que el muro posterior fue levantado con relación a la curvatura de uno de los andenes del periodo inca que vienen del sector Patapata. Torrely y Campana (1994) la describen así:

La planta de esta vivienda en dos niveles se acomodó a la forma del terreno trapezoidal que es cortado por un andén inca, con portada de piedra para el ingreso principal a través de un zaguán, el patio central es también trapezoidal con empedrado de canto rodado en proceso de destrucción, la escalera de piedra con barandas de madera, se acomoda al lado obtuso del trapecio, dando acceso a la balconería corrida de madera en los tres lados, sostenida en uno de ellos por una columna de piedra. En la parte posterior de la edificación se ubica un huerto; la vivienda en general no ha sufrido alteración de su forma y estructura debido a que no ha sido subdividida, la fachada 
cuenta con ventanas simples alineadas que presentan cerrajería de fierro, toda la vivienda se encuentra en regular estado de conservación. (p. 68)

Figura 6. Vista panorámica de la casa Negrón Alonso, obsérvese el mal enrutamiento de los cables que terminan por contaminar su fachada.

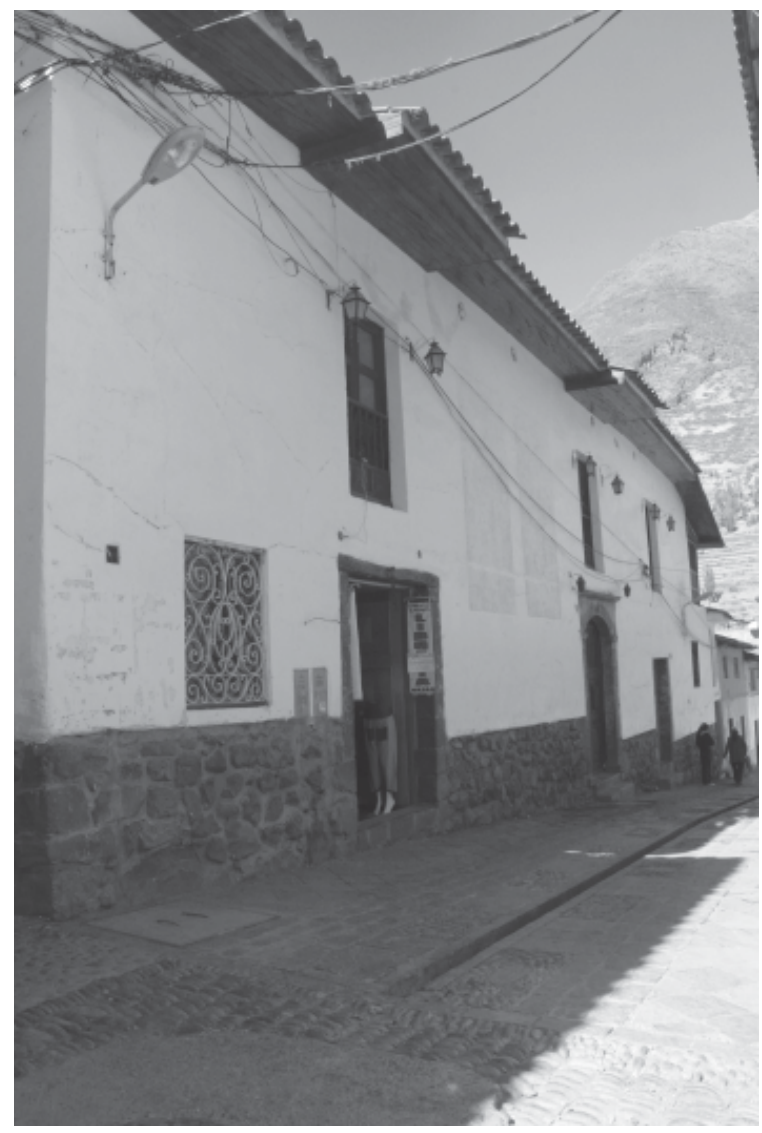

Fuente: Archivo fotográfico personal, 2016.

\section{La casa republicana del siglo $\mathrm{XIX}^{2}$}

Torrely y Campana (1994), mencionan que este periodo se dio entre los años 1830 a 1940 y las describen como:

Viviendas de uno o dos niveles, planta cuadrada o en «L» con patio central generalmente ubicadas en esquinas; se caracterizan por no presentar galerías, la planta del primer nivel se repite por lo general en el segundo nivel, el ingreso principal está en la parte central de la fachada, con portada de piedra y zaguán de acceso, presentan también accesos secundarios a tiendas. La predominancia de vanos en el segundo nivel es de puerta-ventana con balcón a plomo de muro y cierta tendencia a sobresalir, alineados con los del primer nivel. (pp. 71-72)

2 Acápite tomado del Plan Maestro del Distrito de Pisaq, 2005. 
Según el INC, las viviendas se caracterizan por «ser edificaciones (...) con mampostería de adobe y cobertura de teja cerámica, cuyos acabados (...) son escuetos y sencillos» (2005, p. 166). Entre las más representativas y que mejor se conservan tenemos:

- La Casa ubicada en la calle Vigil No 246, con portada cuyo dintel recto de piedra tiene tallada la fecha de 1832 como año de construcción y en cuya dovela central muestra un cristograma con las siglas IHS (del latín: Iesus Hominum Salvator); se encuentra rematado por una cornisa en línea recta sobresaliente y soportada por pilastras de líneas simples y de sección rectangular. Actualmente fue adquirida por la Pontificia Universidad Católica del Perú (PUCP). Tanto exterior como interiormente conserva las características de la época republicana:

Consta de dos plantas de forma cuadrada con patio central, cuyo ingreso principal es por medio de un zaguán con portada de piedra, el patio empedrado con canto rodado está conformado por galerías con arquerías de piedra y escaleras de piedra encajonadas, la fachada presenta ventanas ajenas con enrejados costeños, escarchado de concreto y elementos ajenos, no muestra su original tipología debido a la intervención que ha sufrido todo el inmueble con criterios de restauración muy discutibles. El principal atractivo de esta casa era un molino de piedra de la época colonial, el mismo que no ha sido intervenido. (...) Actualmente se viene construyendo al interior del inmueble en concreto y bloqueta con criterios atentatorios para la imagen volumétrica del poblado. (Torrely \& Campana 1994, p. 67)

- $\quad$ La Casa Marín ubicada en la calle Grau s/n (Figura 7), posee portada de jambas rectangulares con tallados a manera de pilastras pareadas a ambos lados que soportan un dintel y frontón circular partido, edificada el año de 1919. El interior fue refaccionado para la visita turística, se halla en buen estado de conservación y ninguno de sus ambientes fue modificado. De acuerdo a Torrely y Campana (1994):

Vivienda de planta cuadrada con patio central, la fachada a la calle Grau es de un solo nivel con el ingreso asimétrico destacado por una habitación construida sobre el mismo y que sirve para componer la portada de piedra de gran calidad en dos cuerpos y con puerta tallada en madera, es destacable la carpintería de las ventanas en madera con ornamentaciones sobrepuestas y en estilo manierista. El patio está empedrado en canto rodado con influencia del altiplano, al centro tiene un basamento de piedra con barandal de fierro que sirven de base a una palmera, al lado derecho tiene una mampara de madera tallada, en los de más lados los accesos a las habitaciones son por medio de puertas directas cuyo atractivo consiste en la carpintería de madera, con ornamentaciones sobrepuestas en el mismo lenguaje de las ventanas exteriores (...) teniendo como acabado final (...) un enlucido de barro texturado, tanto en la fachada como en el interior. (p. 65)

- Otro inmueble de factura posterior es el perteneciente a la Sra. Carmen Paz, está ubicado en la calle Bolognesi No 214 (Figura 8) el cual data de 1946, se halla en buen estado de conservación, algunos de los ambientes ubicados en el primer piso fueron acondicionados para el comercio, y consta de: 
Figura 7. Vista panorámica de la casona, hallado en buen estado de conservación y adaptado actualmente para la visita turística sin que esto signifique la modificación de los ambientes.

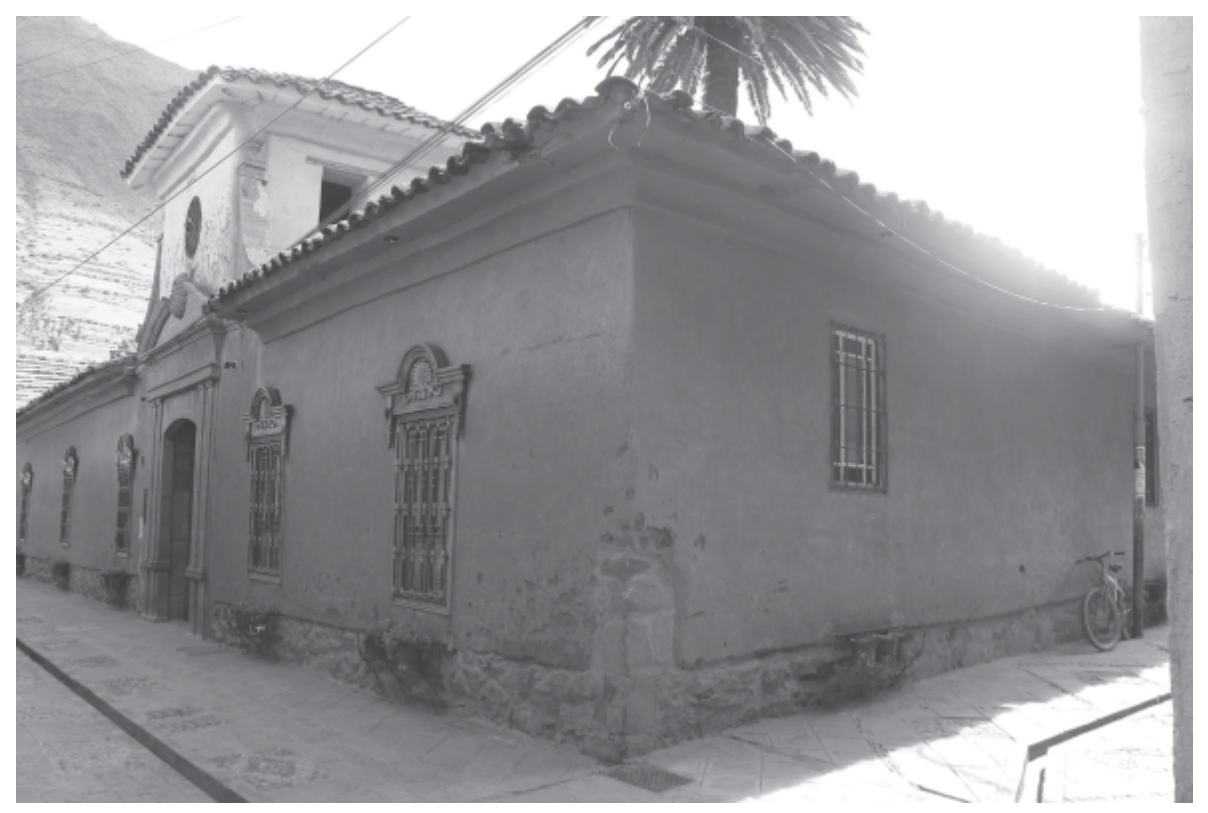

Fuente: Archivo fotográfico personal, 2016.

Planta rectangular a plomo de vía con patio posterior de donde se aprecia un escalera de piedra para el segundo nivel, el ingreso en la parte central por medio de un zaguán con portada de piedra ha sido clausurado para ser alquilado, la estructura de la vivienda se mantiene integra pero ha sido modificada para alquilarla. (Torrely \& Campana, 1994, p. 67)

- El Horno Virreinal denominado San Francisco (equivocadamente hoy conocido como el Horno Colonial) ubicado en la calle Mariscal Castilla No 572 (Figura 9), perteneciente a la familia Marín. Actualmente, el espacio interno fue modificado para la venta de artesanías y alimentos por lo que se hicieron diversas adecuaciones tanto al exterior como al interior. Siendo el año de edificación en 1930 (Torrely \& Campana, 1994). Actualmente es muy visitado por turistas nacionales y extranjeros no solo por la arquitectura del inmueble, sino porque aún mantiene la tradición al momento de elaborar los panes los cuales son muy apreciados a nivel nacional e internacional.

La casa es de planta cuadrada en un nivel con patio central, diseñada para horno de elaboración de pan (...) se ingresa por medio de zaguán central al patio, al frente del ingreso se ubica el horno, espacio de doble nivel y cuya volumetría domina la del inmueble, al lado derecho del patio existe un pórtico, para el depósito de leña, con columnas de piedra de base cuadrada con plinto destacado por su estilo diferente y columnas de corte circular; al lado derecho del patio se ubican habitaciones para uso de los propietarios. La fachada de un nivel destaca el ingreso con un segundo nivel sobre el mismo, es de notaria calidad la uniformidad en el tratamiento de vanos tanto al interior como al exterior del inmueble. (Torrely \& Campana, 1994, p. 65) 
Figura 8. Vista panorámica de la casona, la cual aún conserva la esquina ochavada de la época, se halla en regular estado de conservación por la subdivisión y descuido de sus ambientes.

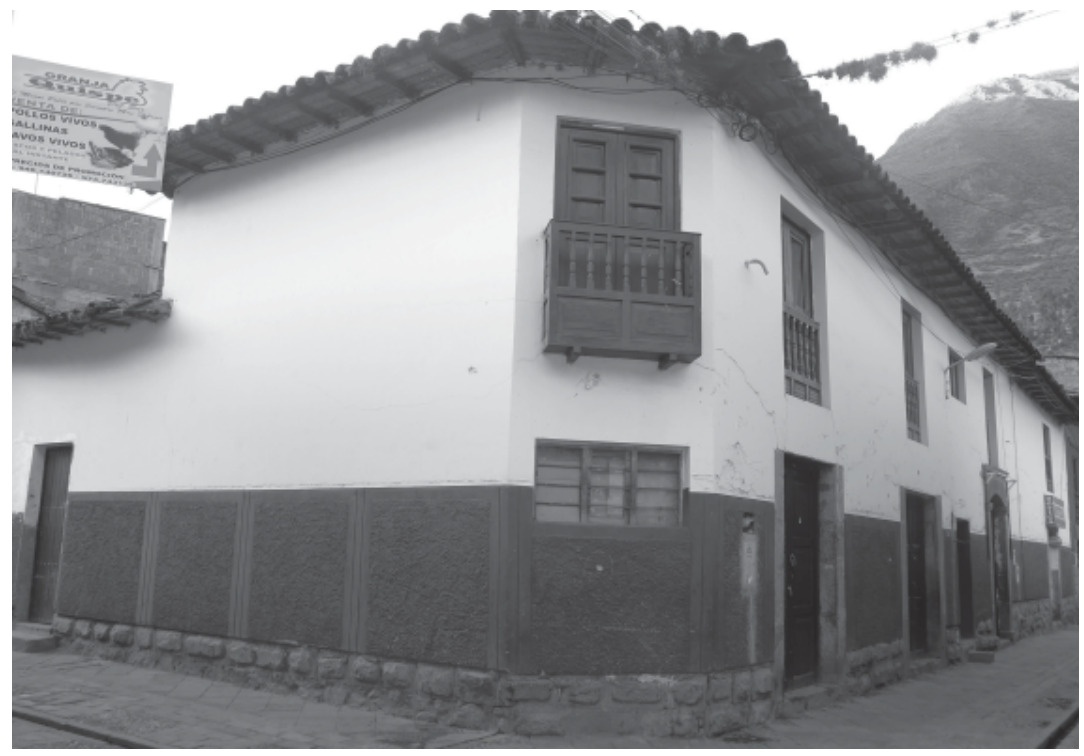

Fuente: Archivo fotográfico personal, 2016.

Figura 9. Vista de la fachada del horno en un día atípico, obsérvese la adecuación de materiales extraños como plásticos que terminan por contaminarlo.

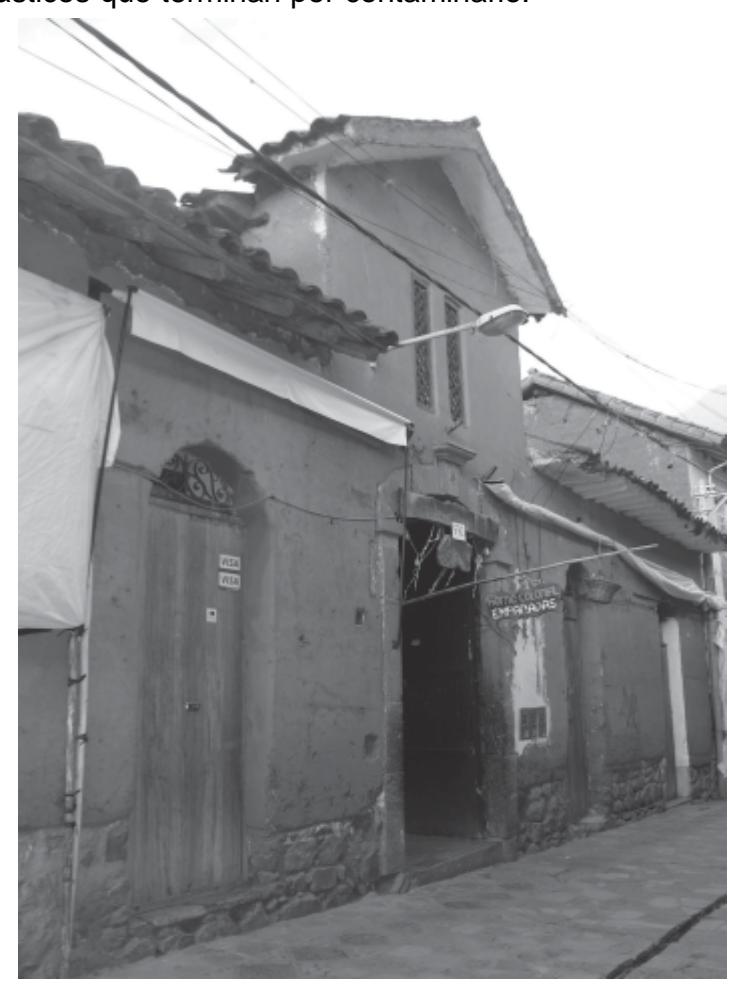

Fuente: Archivo fotográfico personal, 2016. 


\section{La vivienda contemporánea}

De acuerdo a la información del INC (2005, p. 165) se describe que "son edificaciones de 02 o 03 niveles que se caracterizan por presentar mampostería de adobe o de ladrillo u bloqueta arriostrado con un sistema aporticado de vigas y columnas de concreto armado, con cobertura de teja cerámica”. Estas viviendas no resultan ser muy ajenas al contexto tradicional, y como representante de este ejemplo tenemos al Consejo Municipal ubicado en la plaza Constitución construido con materiales nuevos, manteniendo y no rompiendo con las características del entorno tradicional del CHP.

\section{Viviendas atípicas}

Según el INC (2005, pp. 164-165), estas se caracterizan por lo siguiente:

Tener materiales como la calamina, fibra plástica de color, la altura y volumetría de la edificación es excesiva en comparación al contexto que la rodea. Estas unidades de vivienda son producto de la improvisación, subdivisión u fraccionamiento de los inmuebles o predios originales. En su mayoría constituido por edificaciones de un solo nivel o de 03 u 04 pisos.

En la actualidad la mayoría de las viviendas tradicionales están siendo demolidas por hallarse en mal estado de conservación siendo reemplazadas por edificaciones nuevas, los cuales rompen con la arquitectura tradicional del periodo virreinal y republicano del CHP (Figura 10). El turismo convencional trajo consigo el comercio ambulatorio, el aumento desordenado de servicios, la invasión del espacio público, la contaminación visual y por ende la alteración de la configuración urbana.

\section{Valoración cultural desde los actores sociales de Pisaq}

Como se señaló anteriormente, hoy en día la principal actividad económica de Pisaq es la prestación de servicios turísticos y el comercio artesanal, lo que impacta directamente sobre el paisaje urbano por el comercio ambulatorio desordenado, la invasión de espacios públicos, sumado a la construcción de nuevas edificaciones que resultan ser muy ajenas -contextualmente- al entorno tradicional de características virreinales y republicanas. Los efectos negativos de esta actividad lograron transformar el territorio del distrito, pasando de un lugar agrícola a uno turístico, donde más del 60\% de la población se beneficia por la prestación de tales servicios. El CHP todavía es un foco de gran relevancia gracias a su tradicional conformación conservada desde el virreinato, pero hoy en día la valoración patrimonial, planteada desde las mismas instituciones, no preserva sus valores al presentarlos solo mediante criterios rigurosos para ser declarados patrimonio cultural.

El Centro Histórico, destaca por estar ubicado en uno de los accesos principales al Parque Arqueológico de Pisaq, por la arquitectura que lo delimita y por el entorno natural que lo envuelve. Gran parte de la población del distrito trabaja en alguna empresa o se beneficia directamente del turismo que accede al CHP; este sector considera que las obras de reconstrucción de algunas casonas virreinales o republicanas traerían de alguna manera la recuperación de la economía y el aumento del turismo. De todas maneras la preservación del CHP (de quienes están directamente vinculados con el turismo), en opinión de los actores sociales, señalan que sí traería beneficios 
Figura 10. Plano planímetro: delimitación del Centro Histórico de Pisaq.

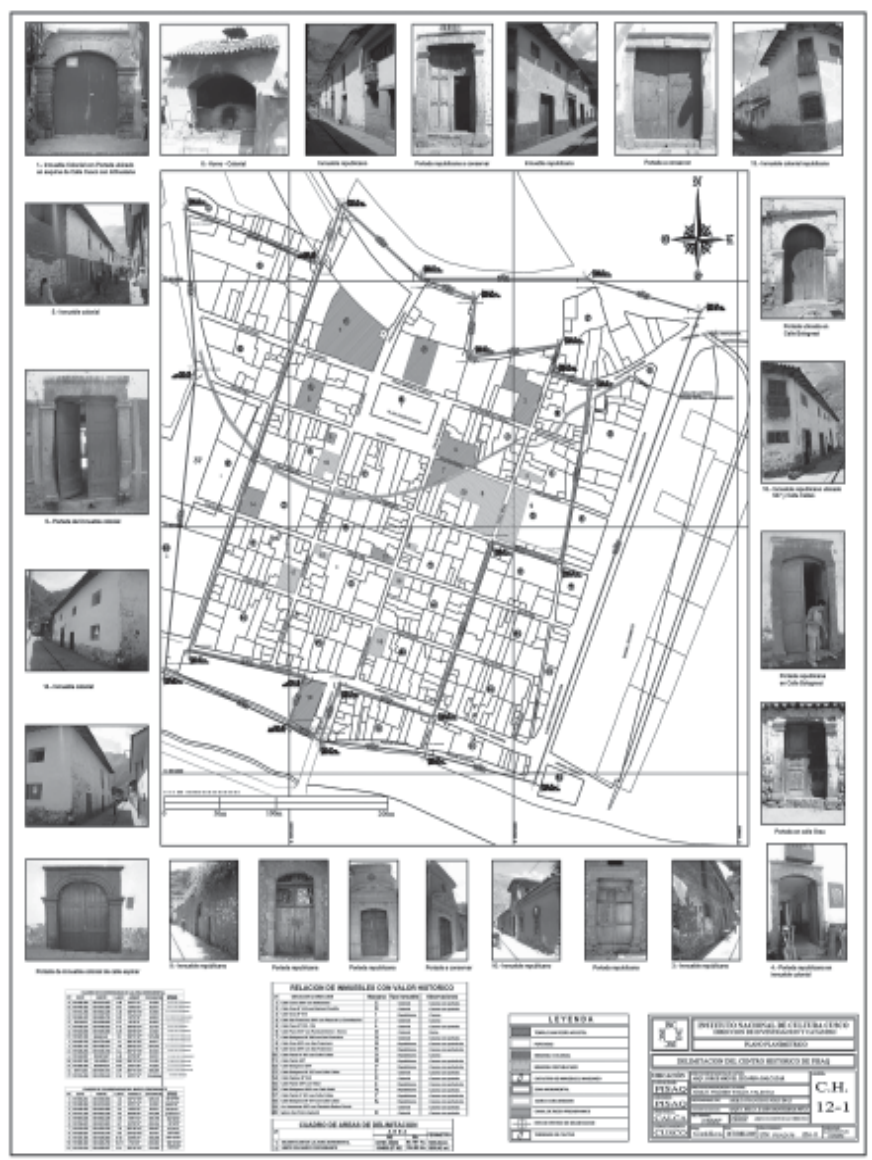

Fuente: Instituto Nacional de Cultura, 2005.

económicos y que el desalojo de los artesanos permitiría el desarrollo de actividades culturales en el centro de la ciudad, en este caso, la plaza de armas (hoy en día, mercado artesanal). Mientras que a los pobladores que se benefician indirectamente de esta actividad, poco o nada les importa la conservación del CHP, considerando el cambio brusco de su imagen como sinónimo de desarrollo.

La valoración patrimonial sobre el CHP, desde esta perspectiva, se ve deteriorada y afecta las relaciones sociales y culturales, generando conflicto entre habitantes, instituciones y autoridades al no existir un centro de interacción por el simple hecho de politizar el "progreso o desarrollo: la sostenibilidad del patrimonio depende en gran medida de políticas y acciones que garanticen la protección” (UNESCO, s.f., p. 132).

\section{Apuntes para su gestión}

En general, hablar de gestión implica referirse al manejo de algo que se administra para que genere los mejores resultados posibles. En el ámbito del patrimonio cultural esta gestión deberá administrar más allá de la superación del deterioro y/o anulación, repotenciando procesos de rehabilitación, reconocimiento y disfrute por 
y para todos, que lo conviertan en un verdadero elemento de desarrollo. Así, es posible definirla como lo proponen Ballart y Tresserras (2001, p. 82): “Conjunto de actuaciones programadas con el objetivo de conseguir una óptima conservación de los bienes patrimoniales y un uso de estos bienes adecuado a las exigencias sociales contemporáneas”. Entendemos la acepción de 'eficacia' en el sentido más amplio del término como la ‘capacidad de lograr el efecto que se desea o se espera’ y proveniente del vocablo latín eficacia (Real Academia de la Española).

La necesidad de una informada toma de decisiones entre un menú de alternativas, ha tenido como consecuencia que las aproximaciones a la gestión patrimonial estén cambiando también. Y para aumentar las potencialidades, resulta imprescindible identificar los valores específicos de los bienes patrimoniales en la perspectiva de decidir cómo gestionarlos adecuadamente sin producir impactos contraproducentes en ellos:

The complexity surrounding heritage should therefore compel society to engage in its holistic management rather than to conserve only specific structures, as happened in the past. With the greatly widened scope of what is regarded as heritage, the increasing complexity of the problems facing it, and the need to use it sustainably, whether for tourism or for other purposes, care of the heritage inevitably involves making decisions about what change is, or is not, acceptable (...) Managing heritage is increasingly demanding and, at the same time, the outputs and outcomes expected from the management processes are ever greater. (UNESCO Word Heritage Centre, Centro Internacional de estudios para la Conservación y Restauración de Bienes Culturales - ICCROM, Consejo Internacional de Monumentos y Sitios - ICOMOS, Unión Internacional para la Conservación de la Naturaleza - IUCN, 2013, p. 2013)

Queda subrayada, entonces, la validez del enfoque gestionario inscrito en un marco más contemporáneo que pretende optimizar el disfrute y goce social de los bienes culturales, y por ende, traspasando claramente los límites de la conservación para instalar el objetivo en su apropiación y puesta en valor social de aquellos para los individuos y comunidades que les dan sentido.

En la misma línea de pensamiento Stefano Bianca se permite reconocer buena parte de la agenda patrimonial contemporánea que asume lo urbano -especialmente en las 'ciudades históricas- no solo como problemas y complejidades, sino como verdaderos desafíos y retos que nos interpelan y convocan activamente:

Historic cities incorporate a promise for the future. For they contain the genetic seeds of certain deep structures and corresponding human practices and processes that the future generations cannot afford to lose... They will thus be able to instil life, social relevance, emotional content and sensorial enjoyment to emerging new urban structures -which otherwise are a risk of remaining stillborn products of a purely abstract imagination, projected into a meaningless reality (...) Spurring the creative imagination capable of overcoming the current divorce between 'conservation' and 'development' would open new and bright perspectives to the concept of historic urban landscapes. (UNESCO Word Heritage Centre, 2010, p. 33) 
En el marco de la situación del poblado de Pisaq y su patrimonio monumental, y a partir de las constataciones ya referidas es posible identificar las siguientes falencias gestionarias:

- Nula priorización de la dinámica cultural entre los considerandos y componentes del Plan de Desarrollo Concertado Provincial de Calca y referencia superficial y marginal en su agenda de actuación estratégica.

- Visible debilidad de las instancias de gobierno (local, regional y nacional), así como en la participación y compromiso social local, que genera falencias en la toma de decisiones y actuaciones para el mejoramiento de situaciones como:

- Conflictos de apropiación del patrimonio cultural arquitectónico y del espacio público.

- Pérdida constante, irreversible y significativa del patrimonio arquitectónico.

- Falta de voluntad política para el uso social del patrimonio arquitectónico y arqueológico en el poblado de Pisaq.

En este punto específico de la aproximación al objeto de estudio resulta ineludible tomar como referencia la: Declaración de Xi'an sobre la conservación del entorno de las estructuras, sitios y áreas patrimoniales (Consejo Internacional de Monumentos y Sitios, 2005) especialmente en los siguientes aspectos:

1. El desarrollo de instrumentos normativos y de planeamiento eficaces, así como de políticas, estrategias y prácticas para gestionar de forma sostenible el entorno, exige también una aplicación coherente y continuada de los mismos, y su adecuación a las particularidades locales y culturales (...)

2. La legislación, la reglamentación y las directrices para la conservación, la protección y la gestión de las estructuras patrimoniales, los sitios y las áreas patrimoniales deben prever la delimitación de una zona de protección o respeto a su alrededor que refleje y contribuya a conservar el significado y el carácter distintivo del entorno.

El desarrollo dentro del entorno de las estructuras, los sitios y las áreas patrimoniales debe contribuir a interpretar positivamente su significado y su carácter distintivo (Consejo Internacional de Monumentos y Sitios, 2005).

En consideración y coherencia a dicho marco es que resulta finalmente posible apuntar algunos lineamientos -entendido como ‘dirección, tendencia' (Real Academia de la Española)- de gestión del patrimonio monumental urbano en temáticas emergentes, especialmente a partir de la sistematización de experiencias que proponen autores de referencia en el ámbito latinoamericano, como Fernando Carrión, Silvio Mendes, Patricia Rodriguez, René Coulomb y Leo Orellana. Los lineamientos de gestión más relevantes se desarrollan a continuación:

Con relación a los marcos de gestión y administración es identificable que la tendencia para el poblado de Pisaq debería pasar por la consolidación y repotenciación de una entidad-líder proveniente de 'lo local', especialmente desde la Municipalidad Provincial de Calca. Son destacables -pero largamente insuficientes- los esfuerzos que se vienen acometiendo para 'facilitar' los procesos de iniciativa privada y pública en la recuperación 
y responden indudablemente a la concepción de un organismo territorial técnico-gestionario, con pretensiones de contar con autonomía con relación a la gestión del conjunto urbano.

Sería sumamente necesario analizar y contar con una 'autoridad autónoma y específica' para su gestión pública. En este sentido, el diseño de un órgano de gobierno y de gestión específico para el poblado de Pisaq capaz de asegurar la coordinación, eficiencia y durabilidad de programas y proyectos constituye todavía un desafío pendiente. Por ello, resulta indispensable la implementación de un dialogo intergubernamental localregional-nacional para la aplicación de los lineamientos, normas y reglamentos que precisen claramente los parámetros de gestión del poblado de Pisaq. En ese marco, se destaca la urgencia de instalar el Comité de Gestión que corresponde, según los requerimientos de planeamiento (Plan específico), que exige el Sector Ministerial de Urbanismo, el cual podrá afrontar de una manera más integral las temáticas de territorio y ambiente, crecimiento urbano, puesta en valor del área urbana con valor patrimonial, espacios públicos, movilidad urbana, zonificación urbana, hábitat, etc. Sin embargo, no es posible obviar la impronta altamente política del escenario recuperatorio del poblado de Pisaq, lo cual resulta una pieza de un discurso que pretende reforzar la imagen de la autoridad local.

Sobre la planificación y sus instrumentos, se observa que existe una voluntad por definir al 'instrumento de planificación’ como referente que soporta la conducción pública del proceso de recuperación, así como la coordinación de la gestión gubernamental local. Sin embargo, debe destacarse que los planes formulados -más allá de su aprobación- resultan avances significativos al integrar planificación territorial, económica, social, ambiental e institucional, aunque con énfasis heterogéneos y otra vez insuficientes. De la misma manera, sería recomendable potenciar más la visión que inserte al poblado de Pisaq como parte del sistema urbano y territorial del Valle en su conjunto. Otra labor pendiente está evidenciada en este caso por la prospección de escenarios: analizar los desarrollos actuales y futuros, planificados - o no- y/o previsibles del contexto y del mismo poblado de Pisaq de cara a definir escenarios diversos y estrategias diversas para esas situaciones. Y finalmente, resulta indispensable una repriorización del Plan de Desarrollo Concertado Provincial de Calca de la dimensión de 'lo cultural' como auténtica estrategia de desarrollo y no como elemento periférico a dicha temática, como se ha venido abordando. En razón de que en la administración territorial del Poblado interviene tanto la Municipalidad (principalmente la Municipalidad Distrital pero también la Municipalidad provincial) como el Ministerio de Cultura.

La elaboración de los instrumentos de gestión y su aplicabilidad debería considerar las competencias de ambos. Un ejemplo de la falta de diálogo al respecto es la 'no aprobación' del Plan de Desarrollo Urbano elaborado en el marco del Proyecto Reordenamiento y Rehabilitación del Valle del Vilcanota por el Proyecto Especial Regional Plan COPESCO (2011), ya que básicamente se suscitó por discrepancias entre ambas instituciones que no concuerdan en aspectos fundamentales como la determinación de las áreas de expansión urbana. Ello es una evidencia más de los conflictos identificables en temáticas como: zona arqueológica-crecimiento urbano, áreas de cultivo-crecimiento urbano, cambio de uso-dinámica urbana (entre las principales), situación a ser resuelta mediante un dispositivo de planeamiento con instrumentos de gestión que articulen eficazmente las competencias de la administración territorial. 
Asimismo, otro punto importante en la implementación de los instrumentos de planificación, es el hecho de que no han sido desarrollados de una manera participativa plena. Dicha problemática -corroborada por varios actores sociales locales en la sesión de campo más reciente que tuvimos allí en 2017- es de tal magnitud que el mismo Plan Maestro del Parque Arqueológico de Pisaq (2005) -actualmente en vigencia- ha sido desacreditado por los abogados de grupos hoteleros de Pisaq, que han encontrado justamente, su punto débil al no poder demostrarse que ha sido elaborado participativamente, que es exactamente lo que exige la norma sectorial nacional. Ello resulta lamentable porque evidencia la ausencia de una mirada integradora de 'gobernabilidad-participación ciudadana', redundando proporcionalmente en la endeble sostenibilidad del patrimonio cultural, situación que debe ser afrontada inmediatamente.

Respecto a los mecanismos legales y financieros, el caso del poblado de Pisaq plantea varias apuestas evidenciadas en el análisis casuístico: la inversión pública está conceptuada como el motor de la recuperación al expresar la existencia de una voluntad política de un mecanismo de 'subsidio territorial' a los intereses específicos del mercado y porque permite asegurar la conducción del proceso en lo relativo a las prioridades de intervención. Sin embargo, en desmedro de los avances significativos, aún no existe una estrategia integral y clara al respecto. Por ende, lo relativo al impuesto a la renta aparece como necesidad urgente, por lo que se impone que el Gobierno nacional factibilice este medio y otros de transferencias de potencial de desarrollo, tal y como reciben otras realidades análogas y que permiten un 'reequilibrio territorial'. Asimismo, entre los dispositivos financieros resultaría estratégica la apuesta por concretar la transferencia total de los fondos recaudados por el boleto turístico Cusco que gestiona el Ministerio de Cultura y que tiene por fin exclusivo la conservación del patrimonio edificado del poblado de Pisaq. Ello puede incidir en la gestión del patrimonio referido. Aquí queda claro que el binomio turismo-cultura es, desde su origen, complejo pero potencialmente valioso, creemos firmemente que sin una estrategia más agresiva y de lógicas de 'ganar-ganar' que expliciten los beneficios de la multiplicidad de actores involucrados, la batalla gestionaria seguirá estando perdida. Queda claro que a partir del reconocimiento de las potencialidades del poblado de Pisaq, la Municipalidad Distrital de Pisaq e incluso el mismo Ministerio de Cultura, enfatizan la perspectiva de que el turismo trae desarrollo, pero sin preguntarse ni plantearse pertinentemente: ¿cuál desarrollo?, ¿y qué tipo de turismo? Es necesario el cambio de paradigma para situar a la cultura y al patrimonio en su rol de factor de desarrollo y no como impedimento de él, como diversos sectores y actores sociales tienden a estigmatizarla, y el caso de Pisaq no es la excepción. Resulta clave atender las disonancias evidentes entre patrimonio cultural y actividad turística, generando un modelo de desarrollo que redefina el rol de las actividades deseables y pondere el rol del turismo en el marco de la dinámica de la ciudad-territorio.

Sobre el aprovechamiento de las oportunidades que representa la Cooperación Internacional, son identificables las deficiencias en virtud a que mayormente no han podido ser capitalizadas dichas oportunidades. Sin embargo, son muy destacables los esfuerzos emprendidos por potenciar una 'cartera de proyectos', lo cual demuestra una cierta capacidad institucional para formular proyectos que puedan movilizar recursos desde diversas fuentes al ser puestos en consideración a los organismos internacionales pertinentes. Así se asegura un lógico y natural tránsito del Plan al Proyecto Urbano. Un aprovechamiento destacable de los evidentes apoyos y oportunidades que la cooperación cultural internacional plantea, lo representaba el muy reciente convenio bilateral suscrito entre la Municipalidad Distrital de Pisaq y el Cabildo de Lanzarote de la provincia de Las Palmas (España) que abre oportunidades de actuación compartida. Justamente, existió la propuesta de conformación de 
comisiones y grupos de trabajo pero hasta la actualidad no se ha logrado concretar. Otras temáticas claves (gestión ambiental, conservación patrimonial, movilidad urbana, turismo sostenible, habitabilidad, gobernabilidad ciudadana) podrían ser apuntaladas desde las posibilidades de acción de la Cooperación Internacional.

\section{Conclusiones}

La significativa valoración cultural de Pisaq que viene siendo afectada principalmente por factores antrópicos, manifestada en el aprovechamiento de su potencial turístico desligado de políticas efectivas que alienten su conservación, requiere un cambio efectivo en su gestión, con el compromiso de los actores involucrados partiendo del liderazgo efectivo de sus autoridades, el actuar responsable de los comerciantes y operadores turísticos y la defensa del patrimonio cultural por parte de la comunidad en su conjunto.

Precisamente, en Pisaq el patrimonio cultural inmueble está representado tanto por sus monumentos edificados, como por el centro histórico que lo contiene y su entorno, constituido este último, por un paisaje cultural y natural de gran significancia y valor; por lo cual, los instrumentos de gestión y acciones de carácter urbanístico deben considerar siempre esta importante condición.

Por ello, es necesario coadyuvar con la protección y/o recuperación del patrimonio cultural de Pisaq, pasa no solamente por la restauración de sus monumentos, sino también por la construcción del marco técniconormativo adecuado que garantice su sostenibilidad, expresado en la elaboración y el cumplimiento de los instrumentos de ordenamiento territorial. En el entendido de conseguir una urbe competitiva, ecológica e inclusiva, que compatibilice e involucre la valoración del patrimonio cultural con tal objetivo, es imperativo elaborar e implementar participativamente los instrumentos urbanísticos necesarios y pertinentes enmarcados en el marco del sistema nacional de planificación territorial. El hacerlo participativamente involucra al gobierno local, nacional (Ministerio de Cultura, Ministerio de Vivienda, Construcción y Saneamiento, Ministerio del Ambiente) y la sociedad civil organizada.

\section{Referencias}

Ballart, J., \& Tresserras, J. (2001). Gestión del patrimonio cultural. Barcelona: Ariel S. A.

Bauer, B. S. (2008). Cuzco antiguo: tierra natal de los Incas (1 $1^{\text {a }}$ ed.). (J. Flores Espinoza, Trad.). Cuzco: Centro de Estudios Regionales Bartolome de las Casas CBC.

Centro Guamán Poma de Ayala. (2011). Plan de Desarrollo Urbano de Pisac. Proyecto de Reordenamiento y Rehabilitación del Valle del Vilcanota (Documento de Trabajo). Cusco, Perú. Documento no publicado.

Consejo Internacional de Monumentos y Sitios. (22 de Octubre de 2005). Pagina Oficial de Icomos Internacional. Recuperado de http://www.icomos.org/charters/xian-declaration-sp.pdf

Instituto Nacional de Cultura - INC. (2005). Plan Maestro del Parque Arqueologico de Pisaq. Documento preliminar, Instituto Nacional de Cultura, Pisaq, Cusco, Perú.

Instituto Nacional de Cultura - INC. (2010). Restauracion, restitucion volumetrica y puesta en valor de MHA: Templo San Pedro Apostol de Pisac- Calca- Cusco. Expediente Técnico Detallado del Instituto Nacional de Cultura. Pisaq, Cusco, Perú. Documento no publicado. 
Kaulicke, P., Kondo, R., Kusada, T., \& Zapata, J. (2003). Agua, ancestros y arqueologia del paisaje. Boletin de Arqueologia PUCP, 27-56. Ministerio de Comercio Exterior y Turismo. (2007). Proyecto: Reordenamiento y Rehabilitación del Valle del Vilcanota Cusco. Cusco.

Navarro, R. (2014). Estado del arte del patrimonio, la planidicacion urbána y el desarrollo sostenible de la región Cusco (1 ${ }^{\text {a }}$ ed.). Fundación Universitaria para la investigación, desarrollo, ciencia y cultura San Antonio Abad del Cusco (FUNSAAC), Convenio CIUF/ CUD - UNSAAC. Cusco: FUNSAAC.

Rostworowski, M. (1999). Historia del Tahuantinsuyu (2 ed.). Lima: FIMART S.A.C.

Torrely, A., \& Campana, J. (1994). Esquema de ordenamiento urbano del poblado de Pisaq (Tesis de licenciatura). Universidad Nacional de San Antonio Abad del Cusco, Cusco, Perú.

UNESCO. (s.f.). Indicaciones UNESCO de la Cultura para el Desarrollo. Patrimonio, 132-140.

UNESCO Word Heritage Centre. (2010). Managing Historic Cities. París: UNESCO.

UNESCO Word Heritage Centre, Centro internacional de estudios para la conservación y restauración de bienes culturales (ICCROM), Consejo internacional de monumentos y sitios (ICOMOS), Unión internacional para la conservación de la naturaleza (IUCN). (2013). Managing cultural World Heritage. París, Francia.

\section{Anli Chalco Salas}

Licenciada en Arqueología, egresada de la Universidad Nacional San Antonio Abab del Cusco, inscrita en el Colegio Profesional de Arqueólogos del Perú. Trabajó en proyectos de investigación arqueológica del Programa Qhapaq Ñan, en evaluaciones arqueológicas de inmuebles ubicados en el Centro Histórico del Cusco, así como en diversos monitoreos arqueológicos. Graduada de la Universidad Nacional Mayor de San Marcos de Lima, en la Maestría en Gestión del Patrimonio Cultural. Cuenta con una publicación reciente en el Congreso Internacional sobre Paisajes Culturales y Gestión del Territorio. Título: El Deterioro del Soporte Paisajístico. La Importancia de los Sistemas de Andenerías en Pisaq. pp. 64-87, Ministerio de Cultura, Lima 2017.

inkanli.dec@gmail.com

Ángel Delgado Flores

Arquitecto por la Universidad Nacional San Antonio Abad del Cusco, inscrito en el Colegio de Arquitectos del Perú. Proyectista e investigador independiente. Se desempeñó como asistente técnico en la Dirección de Patrimonio Histórico Monumental y Turismo de la Municipalidad Metropolitana de Lima; así también en la Dirección Desconcentrada de Cultura-Cusco y actualmente labora como Coordinador Técnico de la Subgerencia de Ordenamiento Territorial de la Municipalidad Provincial del Cusco. Posee estudios de postgrado concluidos en la Universidad Nacional de Ingeniería de Lima, en la Facultad de Arquitectura, Urbanismo y Artes, específicamente en la Maestría en Restauración de Monumentos en Arquitectura y Urbanismo. Cuenta con una publicación reciente en el Boletín Informativo № 5 Territorio, titulado: El patrimonio cultural edificado y su relevancia en el proceso de elaboración del Plan de Desarrollo Metropolitano de Cusco, Cusco, agosto del 2017.

angeldelgado@outlook.com

José Hayakawa Casas

Universidad Nacional de Ingeniería

Arquitecto, Magíster en Arquitectura con mención en Renovación Urbana (Universidad Nacional de Ingeniería). Investigador y docente de la Universidad Nacional de Ingeniería en Pregrado y en sus Maestrías en Regeneración urbana y de Conservación del patrimonio edificado; en la Maestría en Gestión del patrimonio cultural de la Universidad Nacional Mayor de San Marcos y en la Maestría en gestión cultural, patrimonio y turismo de la Universidad San Martín de Porres. Es Vicepresidente de ICOMOS-Perú y miembro asociado del Grupo de Estudios de la Inmigración Japonesa al Perú S. XVII-XX del Instituto Riva Agüero de la Pontificia Universidad Católica del Perú. Laboró como especialista en Regeneración urbana y patrimonio del Plan Metropolitano de Desarrollo Urbano de Lima al 2035 y actualmente se desempeña como Director del Instituto de Conservación del Patrimonio "Víctor Pimentel Gurmendi" de la Facultad de Arquitectura de la UNI. Cuenta con una publicación reciente en la Revista Turismo y Patrimonio, titulada: Gestionando el patrimonio edificado de Lima. Apuntes para la construcción de un marco teórico, № 10, Lima, setiembre 2016 (pp. 29-39).

josehayakawa@gmail.com 